\title{
Impact of slaking shale behaviour on damage of engineering structures, Saudi Arabia
}

Abd-Alrahman Embaby PhD

Associate Professor, Department of Geology, Faculty of Science, Damietta University, Damietta, Egypt

Ayman Abu Halawa PhD

Associate Professor, Physical Concentration Department, Production Sector, Nuclear Materials Authority, Cairo, Egypt (Orcid:0000-0003-1142-1524)

(corresponding author: halawa1970@yahoo.com)
Medhat Ramadan PhD

PhD student, Department of Geology, Faculty of Science, Damietta University, Damietta, Egypt

\begin{abstract}
Shale slaking has caused problems on infrastructure and buildings in Tabuk City, Saudi Arabia. Most of these problems occur in the form of subsidence, cracking and loss of bearing capacity related to the slaking more than the expansion of clay minerals in shale. The aim of this research is to study the possible causes of such problems in Tabuk districts. The geotechnical properties of Tabuk shale indicate that the shale has a low degree of expansion. X-ray diffraction analysis confirms that kaolinite is the predominant clay mineral, while expansive clay minerals are not present. Based on slake durability index, disintegration ratio and shale rating system, the shale is classified as soil-like with low to medium durability. Scanning electron microscopy results indicate that the development of gypsum crystals could be a crucial factor in the degradation. Pore-air compression and crystal growth or the dissolution of gypsum and halite minerals are significant slaking mechanisms in triggering the disintegration of shale because they disturb the structure and destroy the diagenetic bonds of shale, which reduces the strength. The damage is not related to the expansion of clay minerals within the shale but is significantly influenced by the slaking of shale and its transition from rock-like to soil-like material.
\end{abstract}

\section{Notation}

$A_{\mathrm{c}} \quad$ activity

$D_{\mathrm{R}} \quad$ disintegration ratio

$e_{0} \quad$ initial void ratio

$G_{\mathrm{s}} \quad$ specific gravity

$I_{\mathrm{d}} \quad$ slake durability index

$I_{\mathrm{d} 2} \quad$ second-cycle slake durability index

$I_{\mathrm{d} 5} \quad$ fifth-cycle slake durability index

$I_{s(50)} \quad$ point-load index

$m_{n} \quad$ oven-dried weight of the retained portion of the sample after the $n$th cycle

$m_{\mathrm{o}} \quad$ initial oven-dried weight of the sample

$S_{\mathrm{p}} \quad$ swell potential

$V_{\mathrm{d}} \quad$ sediment volume in distilled water

$V_{\mathrm{k}} \quad$ sediment volume in kerosene

$\rho_{\mathrm{d}} \quad$ dry density $\left(\mathrm{g} / \mathrm{cm}^{3}\right)$

\section{Introduction}

Shale is the dominant sedimentary rock worldwide. Considering its abundance, many cities have been constructed on shale, and it is frequently used as a construction material. However, shale can be fissile and laminated, which makes it prone to slaking owing to environmental changes and prolonged wetting and drying cycles. This can cause severe damage to buildings and infrastructures built on shale. Thus, the required major remedial work and maintenance cycles result in higher maintenance costs than those needed for the initial construction.

In Tabuk City, Kingdom of Saudi Arabia (KSA), Tabuk shale extends over a broad section of the central and northern regions of the city (Figure 1), and its flat terrain has made this area attractive for buildings for urban development. Owing to the rapid urban development of Tabuk City, new districts such as Al Qadisyah, Al Masif, Al Nakhil and Al Nahdah have been extended and built on shale layers (Figure 2). However, significant foundation and structural problems have developed in several large buildings constructed in these districts (Sabtan, 2005). Buildings such as residential buildings, schools and hospitals and infrastructure such as roads and tunnels have reported heaving floors; cracked walls, structural elements and sidewalks; landslides of tunnel walls; and fissure and cracks in roads (Figure 3).

Despite the importance of Tabuk shale from an engineering perspective, most research is concentrated on its swelling characteristics. Few studies have been conducted to characterise the durability properties of the shale or to identify the processes leading to the slaking. Previous research (Dafalla and Al-Shamrani, 2012; Sabtan, 2005; Slater, 1983) has attributed these problems in Tabuk shale to its content of expansive clay minerals such as smectite. However, the proportion of these minerals is very small; rather, nonexpansive clay minerals such as kaolinite and illite are dominant.

Shale crumbles and degrades over time when exposed to wetting and drying cycles. This process is known as slaking or disintegration, which often results in dissolution, the development of cracks and voids and flaking of surface layers (Santi and Koncagül, 1996).

Shale exhibits good mechanical properties and usually shows acceptable engineering behaviour immediately after construction. 


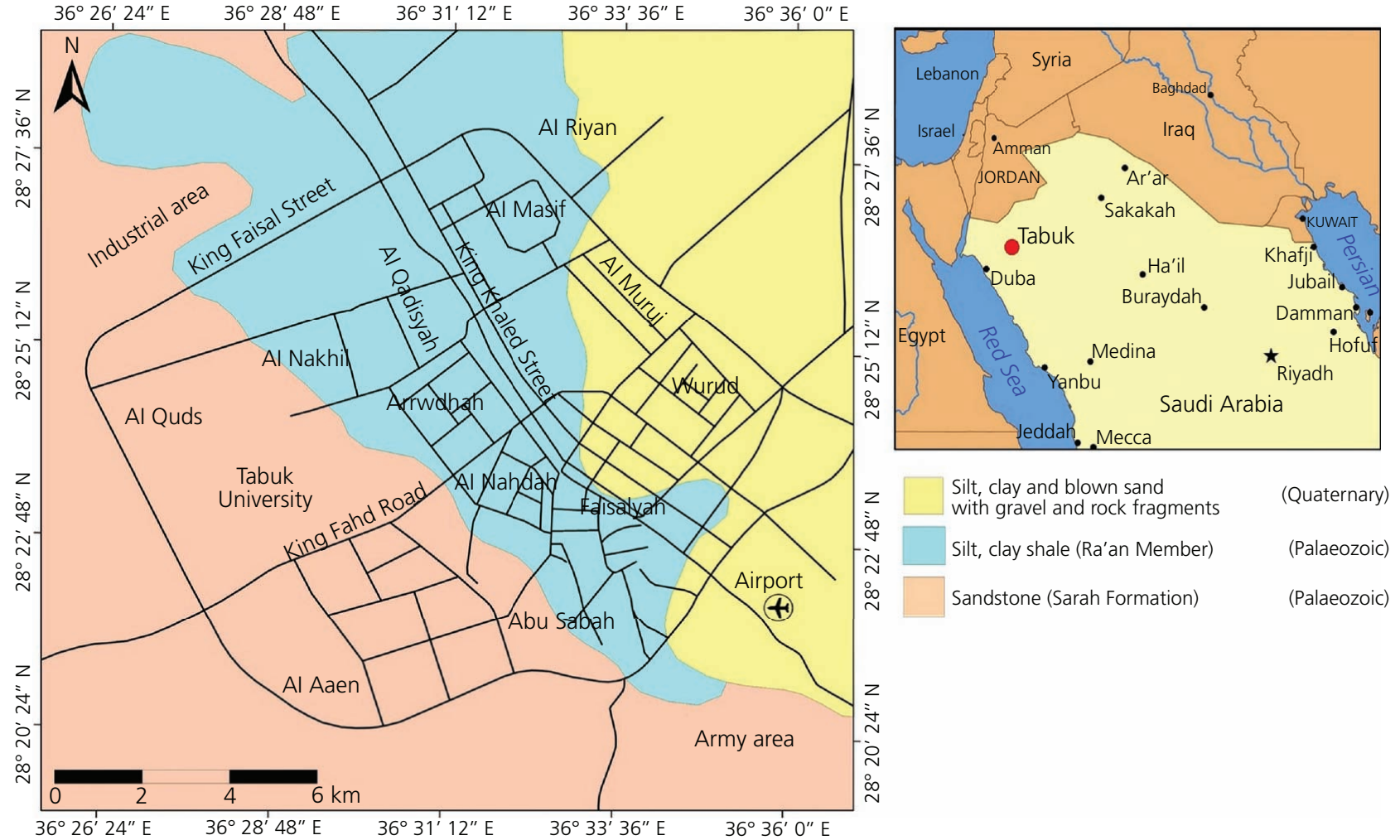

Figure 1. Geological map showing the spatial distribution of shale in Tabuk City, Tabuk, KSA (Embaby et al., 2017)

However, its durability and therefore its strength tend to deteriorate over time when exposed to moisture variation conditions, particularly prolonged wet and dry cycles. Durability affects the mechanical behaviour of shale. In particular, up to $80 \%$ of its shear strength and compressibility can be decreased as a result of slaking and softening (Berisavljević et al., 2018;
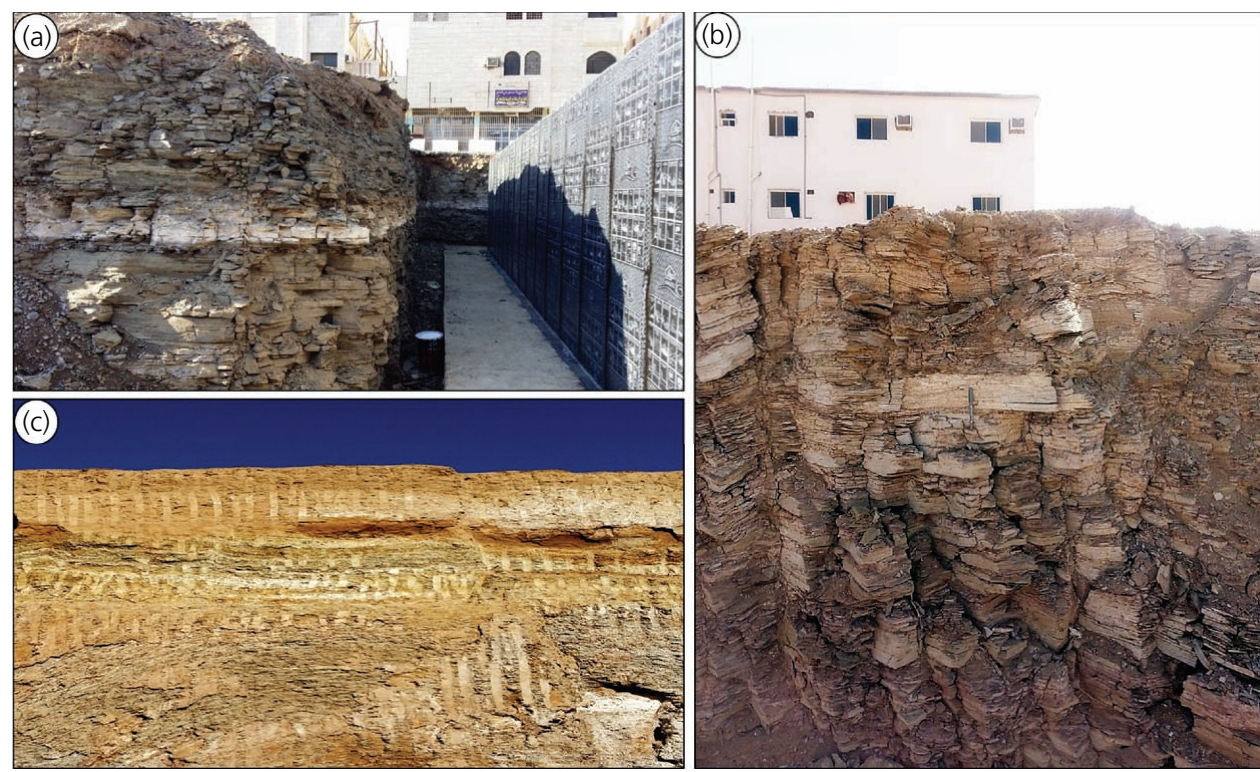

Figure 2. Photographs showing the slaking phenomena in shale layers in Tabuk, KSA: (a) shale slaking beneath a bridge foundation (ground surface to depth $>3 \mathrm{~m}$ ); (b) shale slaking beneath a building; (c) shale slaking and transformation to soil 

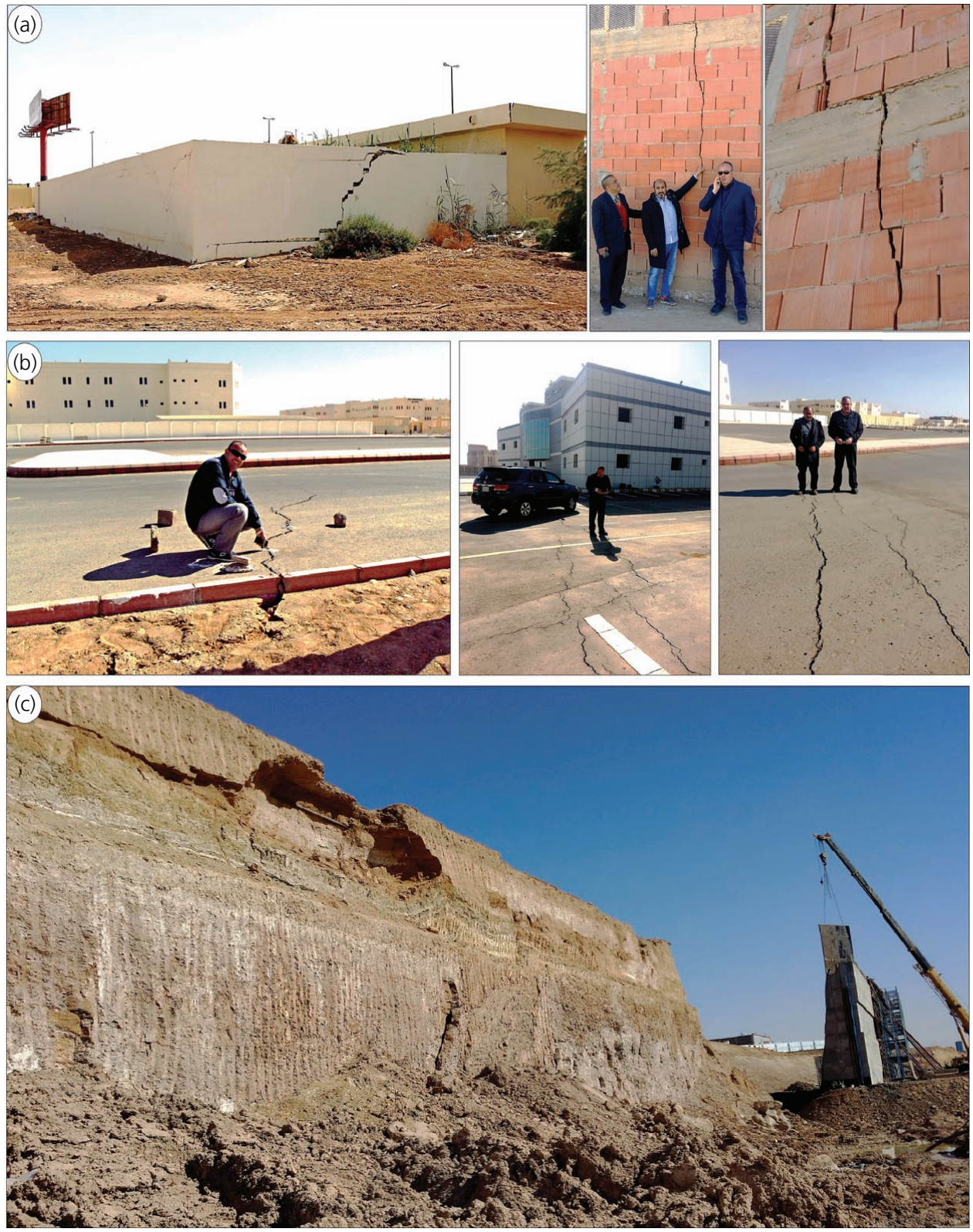

Figure 3. Photographs showing various geotechnical problems in the shale in Tabuk districts, Tabuk, KSA: (a) cracks in walls and structural elements (beam) of a building; (b) fissures and cracks in roads; (c) landslide in the side of a tunnel

Skempton, 1964), which consequently leads to failure of buildings and road embankments as well as slope instability. Thus, it is critical to identify the mechanisms leading to slaking.

Owing to its physical interdependence between durability and slaking, the durability of shale is commonly measured by slaking tests (Santi, 1998). Accordingly, the slake durability index $\left(I_{\mathrm{d}}\right)$ test is the most often recommended for the assessment and classification of the slaking behaviour of clay-bearing rock (Heidari et al., 2016; Gautam and Shakoor, 2017; Richardson, 1985; Santi, 1998). The $I_{\mathrm{d}}$ and disintegration ratio $\left(D_{\mathrm{R}}\right)$ are used for characterisation, quantification of the amount of slaking and assessment of the durability of Tabuk shale. These tests provide information on the durability as well as the strength of the shale. Because durability is an essential factor in determining the strength of a rock (Koncagul and Santi, 1999), it is crucial to identify the factors affecting the durability of Tabuk shale. In order to achieve such objectives, geotechnical index properties such as particle size distribution, moisture content (MC), plasticity index (PI), dry density, porosity and swelling potential; mineralogical composition; and fabric are examined in this study. 
In the current study, the slaking behaviour of shale in Tabuk City is evaluated, and a new approach is presented to diagnose the problems that cause deformations of the buildings and infrastructure built on or containing this shale.

\section{Geology and hydrology}

Geologically, the shale layers in the present investigation belong to the Ra'an Shale Member within the Late Ordovician Qasim Formation, which were deposited in a marine environment ranging from outer shelf to lower shoreface (Kaminski et al., 2019; Senalp and Al-Duaiji, 2001). The Ra'an Shale is widespread in the middle part, narrow to the south and wider towards the northern border of the city (Figure 1). The shale extends to depths greater than $20 \mathrm{~m}$ and is light brown to light greyish in colour. Moreover, it is fissile and silty and has disseminated gypsum. It is covered in some places of the city by layers of sandy loam, clay and recent alluvium $0.2-3.0 \mathrm{~m}$ in thickness. The shale layer outcrops are generally weathered. The thickness of the subsurface weathered shale varies from 0.5 to more than $3 \mathrm{~m}$. The shale layers contain some lenses and veinlets of gypsum and halite minerals. The groundwater table is absent up to the maximum drilled depth $(10 \mathrm{~m})$, although perched water is present in the shale layers from the infiltration of rainfall, leakage from sewage or water pipes and irrigation of gardens.

Tabuk City has an arid climate, with temperatures ranging from about $47^{\circ} \mathrm{C}$ in summer to $-2^{\circ} \mathrm{C}$ in winter with average values of 28 and $12^{\circ} \mathrm{C}$, respectively. The average relative humidity is $33 \%$, and the potential evapotranspiration is $1800-2000 \mathrm{~mm} /$ year. The average annual rainfall is $39 \mathrm{~mm}$, and intense rainfall sometimes causes flooding. Several floods have occurred in Tabuk City, such as those in 1981, 1988, 2008, 2010, 2012, 2013 and 2016, which caused substantial problems for the infrastructure and for residents (Abdulkarim et al., 2019; Embaby et al., 2017). The topography of Tabuk City shows high lands towards the south, east and west and relatively lower elevations with a general slope towards Qa'a Sharawra to the north. The terrain of the shale locations is flat, beginning from the middle district to the northern border of Tabuk City; the slope is nearly $0.0002 \mathrm{~m} / \mathrm{m}$ (Embaby et al., 2017). Generally, many valleys pass through Tabuk City such as valleys Abu Nushayfah, Na'am, Al Baqqar, Dab'an and Al Ghuwaul, and the city is considered as an outlet of these valleys. Dab'an valley runs in the centre of the city over the shale strata. The areas of shale layers in the northern districts are prone to flooding, and the climate and run-off accelerate the disintegration of the Tabuk shale.

\section{Materials and methods}

Sample collection

Shale samples were recovered from the drilled borehole cores in Al Qadisyah District, located at $256517 \mathrm{~m} \mathrm{E}$ and $3148235 \mathrm{~m} \mathrm{~N}$ (WGS 84/UTM zone $37 \mathrm{~N}$ ), to obtain relatively fresh samples. A double-tube barrel with an HQ-sized core diameter of $63.5 \mathrm{~mm}$ was used to recover the shale samples. Four shale samples were taken from different depths of $1.5 \mathrm{~m}(0-1.5 \mathrm{~m}), 3.0 \mathrm{~m}, 4.5 \mathrm{~m}$ and $6.0 \mathrm{~m}$ to represent the most common depths used for constructing the foundations, as well as the depth of the active zone of MC oscillation.

\section{Sample processing and measurements \\ Geotechnical properties}

The geotechnical properties of Tabuk shale samples were evaluated according to the standard procedures of the American Society for Testing and Materials (ASTM, 2016a, 2016b, 2016c, 2016d, 2016e, 2016f, 2016g). The dry density $\left(\rho_{\mathrm{d}}\right)$ was determined using a Jolly balance apparatus. The specific gravity $\left(G_{\mathrm{s}}\right)$ and $\mathrm{MC}$ were determined according to ASTM D 854 (ASTM, 2016a) and ASTM D 2216 (ASTM, 2016b), respectively. The initial void ratio $\left(e_{\mathrm{o}}\right)$ was calculated from the bulk density, water content and specific gravity of the solids. The grain size distribution of shale samples was determined through sieving and hydrometer analysis following ASTM D 422 (ASTM, 2016c). The results were used to determine the distribution of clay-sized particles for use in the geotechnical classification and durability investigations. The testing of Atterberg limits - that is, liquid limit (LL), plasticity limit (PL), PI and shrinkage limit (SL) - was conducted on materials passing through a $425 \mu \mathrm{m}$ sieve following ASTM D 4318 (ASTM, 2016d). The activity of the shale (activity index) was defined according to the paper by Skempton (1953) as activity $\left(A_{\mathrm{c}}\right)=\mathrm{PI} /$ percentage of clays finer than $2 \mu \mathrm{m}$.

Prakash and Sridharan (2004) defined the free swell ratio (FSR) as the ratio of equilibrium sediment volume of $10 \mathrm{~g}$ oven-dried soil passing a $425 \mu \mathrm{m}$ sieve in distilled water $\left(V_{\mathrm{d}}\right)$ to that in kerosene $\left(V_{\mathrm{k}}\right)$. Thus, the FSR can be calculated as FSR $=V_{\mathrm{d}} / V_{\mathrm{k}}$.

The free swell was determined using a one-dimensional (1D) consolidation test, and the free swell of the core shale samples was measured according to ASTM D 4546, Method B (ASTM, 2016e). Point-load tests were conducted according to ASTM D 5731 (ASTM, 2016f) to determine the point-load index $I_{\mathrm{S}(50)}$ related to the strength of rock, which was used for shale classification.

Slake durability index $\left(I_{\mathrm{d}}\right)$ and disintegration ratio $\left(D_{\mathrm{R}}\right)$

The slake durability test was conducted according to ASTM D 4644 (ASTM, 2016g) and the International Society for Rock Mechanics (ISRM) standards (ISRM, 2007). Five cycles were performed to ensure complete disintegration of the shale samples, which was useful in evaluating and classifying the durability of the shale. Previous research studies (Berisavljević et al., 2018; Gamble, 1971; Gautam, 2012; Zhu and Deng, 2019) suggest that more than two standardised cycles of wetting and drying, usually between three and ten cycles, can be performed for rocks of higher durability. The test procedure is described as follows.

To test each shale sample, ten representative shale lumps were used, shale lump having rounded corners and a mass of 40-60 g; the total mass of the sample was $450-550 \mathrm{~g}$. The sample was 
oven-dried and placed in a test drum with a $2 \mathrm{~mm}$ wire mesh (sieve number 10). The drum was rotated in a tank filled with water $20 \mathrm{~mm}$ below the drum axis for $10 \mathrm{~min}$ at a rate of 20 revolutions per min. Afterwards, the sample and drum were removed, and the sample was oven-dried for $16 \mathrm{~h}$ at $105^{\circ} \mathrm{C}$ and was then weighed. A photograph of the retained material was taken, and a standard verbal description was made. These processes were repeated five times. The slake durability index $\left(I_{\mathrm{d}}\right)$ was then calculated by using the following equation from ASTM D 4644 (ASTM, 2016g):

1. $I_{\mathrm{d} n}=m_{n} / m_{\mathrm{o}} \times 100 \%$

where $m_{n}$ is the oven-dried weight of the retained portion of the samples after the $n$th cycle and $m_{\mathrm{o}}$ is the initial oven-dried weight of the samples.

The oven-dried weight of the slaked sample was recorded, and the particle size distribution was analysed by using the following sieve sizes: $25,20,10,5,2$ and less than $2.0 \mathrm{~mm}$. The particle size distribution was used to determine the disintegration ratio $\left(D_{\mathrm{R}}\right)$.

The disintegration ratio $\left(D_{\mathrm{R}}\right)$, proposed by Erguler and Shakoor (2009), was used to assess and quantify the disintegration degree of shale samples. It is defined as the area under the particle size distribution curve of the slaked fragments of a given shale sample divided by the total area encompassing the particle size distribution curves of all slaked shale samples. The following equation is used to calculate the disintegration ratio:

\section{2. $D_{\mathrm{R}}=\mathrm{AC} / \mathrm{AT}$}

where $D_{\mathrm{R}}$ is the disintegration ratio; AC is the area under the particle size distribution curve of a given sample; and AT is the total area encompassing the particle size distribution curves of all samples.

\section{X-ray diffraction analysis}

Clay mineral content in the shale was identified by using X-ray diffraction (XRD). The samples were centrifuged to separate the clay fractions $(<2 \mu \mathrm{m})$. Three slides were prepared for the analysis, with the first slide untreated, the second slide wetted by glycerol and the third heated to $550^{\circ} \mathrm{C}$. The analysis was conducted at the Central Laboratories Sector of the Egyptian Mineral Resources Authority using a PANalytical X'Pert Pro XRD system with a monochromator, copper $(\mathrm{Cu})$ radiation $(l=$ $1.542 \AA$ ) of $50 \mathrm{kV}$ at $40 \mathrm{~mA}$ and a scanning speed of $0.02 \%$. The reflection peaks between $2 \theta=2$ and $60^{\circ}$, corresponding spacing $(d, \AA)$ and relative intensities $\left(I / I^{\circ}\right)$ were obtained. The XRD charts were compared with the International Centre for Diffraction Data database to identify the clay minerals. The amount of minerals present in the samples was quantitatively estimated using areas under the peaks.

\section{Scanning electron microscopy}

The assessment of the fabric and microstructure of the shale was performed by using scanning electron microscopy (SEM) based on images taken by a field-emission gun (FEG; Quanta 250) equipped with an energy-dispersive $\mathrm{X}$-ray unit to analyse the elemental composition of the samples, with an accelerating voltage of $30 \mathrm{kV}$, a magnification of $\times 14$ up to $\times 1000000$ and a $1.0 \mathrm{~nm}$ resolution for the FEG. Each sample was held in an aluminium sample holder and was sputter-coated with a fine film of gold to prevent charging for samples analysed in the secondary electron mode.

\section{Results}

Geotechnical index and mineralogical properties of shale The durability of shale depends on its physical properties; lithological characteristics; mineralogical composition, including non-clay and clay minerals; and geotechnical properties, including particle size distribution, Atterberg limits, Unified Soil Classification System (USCS) classification, SL, activity, dry density, specific gravity, void ratio, free swelling index (FSI) and 1D odometer free swell potential. These properties are summarised in Table 1.

The dominant particle size in Tabuk shale is silt, ranging from 48 to $68 \%$ with an average of $58 \%$, followed by clay-sized particles ranging from 29 to $51 \%$ with an average of $34.4 \%$. The dry density of the studied shale samples varied from 1.91 to $2.10 \mathrm{~g} / \mathrm{cm}^{3}$ with an average value of $2.01 \mathrm{~g} / \mathrm{cm}^{3}$, and the specific gravity values were close to 2.74 . The calculated initial void ratio $\left(e_{\mathrm{o}}\right)$ of the shale varies between 0.30 and 0.44 , which indicates high porosity. Putera et al. (2017) concluded that the void ratios of shale are 0.08-0.50. Furthermore, an inverse relationship between the void ratio and the total vertical stress was noted such that as the total vertical stress increases, the void ratio tends to decrease under the overburden pressure.

The XRD analysis of the bulk samples shows that the mineralogical composition of the shale consists of $51-62 \%$ clay minerals (kaolinite + illite + chlorite), 18-37\% muscovite, 5-10\% quartz, $4-12 \%$ gypsum and minor amounts of goethite and manganese (Table 1). Gypsum occurs as nodules, lenses and microscopic fibres or granular particles. On the other hand, the clay minerals consist of mainly kaolinite (58-80\%), illite (20-39\%) and chlorite (10-14\%; Figure 4). As indicated in Table 1, kaolinite and illite are the dominant non-expansive clay minerals; expansive clay minerals such as montmorillonite were not found. Muscovite is the major non-clay constituent in Tabuk shale. Based on the clay-size percentage and mineral constituents, this shale can be geologically classified as micaceous siltshale (Pettijohn, 1957).

The LL and PL were about 33-35 and 23-26\%, respectively, and the PI ranged from 7 to $12 \%$. The results of the Atterberg limit analysis of the shale samples correlated with the potential swell criteria proposed by Holtz and Gibbs (1956). It is clear from the comparison that Tabuk shale has a low swell potential. 
Table 1. Mineralogical composition and geotechnical properties within depths of Tabuk shale, Tabuk, KSA

\begin{tabular}{|c|c|c|c|c|c|c|}
\hline Parameters & Description & Result & $1.5 \mathrm{~m}$ & $3.0 \mathrm{~m}$ & $4.5 \mathrm{~m}$ & $6.0 \mathrm{~m}$ \\
\hline \multirow[t]{8}{*}{ Mineralogical compositions } & \multirow[t]{4}{*}{ Non-clay minerals } & Muscovite: \% & 32 & 37 & 28 & 18 \\
\hline & & Quartz: \% & 5 & 5 & 5 & 10 \\
\hline & & Gypsum: \% & 7 & 1 & 4 & 12 \\
\hline & & Goethite: \% & 5 & 2 & 1 & 1 \\
\hline & \multirow[t]{4}{*}{ Clay minerals } & Total clay minerals: \% & 51 & 55 & 62 & 59 \\
\hline & & Kaolinite: \% & 58 & 72 & 80 & 66 \\
\hline & & Illite: \% & 32 & 28 & 20 & 20 \\
\hline & & Chlorite: \% & 10 & - & - & 14 \\
\hline \multirow[t]{16}{*}{ Geotechnical properties } & \multirow[t]{3}{*}{ Particle size analysis } & Sand (4.36-0.074 mm): \% & 5 & 2 & 15 & 1 \\
\hline & & Silt (0.047-0.002 mm): \% & 64 & 68 & 54 & 48 \\
\hline & & Clay < 0.002 mm: \% & 31 & 30 & 31 & 50 \\
\hline & \multirow[t]{3}{*}{ Atterberg limits } & LL: \% & 33 & 35 & 34 & 35 \\
\hline & & PL: \% & 26 & 23 & 23 & 24 \\
\hline & & PI: \% & 7 & 12 & 11 & 11 \\
\hline & Shrinkage limit & SL: \% & 15 & 12 & 15 & 15 \\
\hline & USCS classification & & $M L$ & $\mathrm{CL}$ & $C L$ & $C L$ \\
\hline & Activity & $A_{c}: \%$ & 0.23 & 0.40 & 0.35 & 0.22 \\
\hline & Natural MC & NMC: \% & 2.40 & 3.20 & 3.5 & 3.70 \\
\hline & Dry density & $\rho_{\mathrm{d}}: \mathrm{g} / \mathrm{cm}^{3}$ & 2.09 & 1.91 & 2.12 & 2.10 \\
\hline & Specific gravity & $G_{\mathrm{s}}: \%$ & 2.73 & 2.75 & 2.73 & 2.73 \\
\hline & Initial void ratio & $e_{0}: \%$ & 0.31 & 0.44 & 0.29 & 0.30 \\
\hline & Free swelling index & FSI: \% & 7.40 & 11.10 & 6.70 & 7.40 \\
\hline & Free swell ratio & FSR: \% & 1.07 & 1.01 & 1.04 & 1.07 \\
\hline & Swelling potential at $9.8 \mathrm{kPa}$ & $S_{\mathrm{p}}: \%$ & 1.12 & 1.75 & 1.55 & - \\
\hline
\end{tabular}

The FSI values of the Tabuk shale samples varied from 6.7 to $11.1 \%$ with an average of $8 \%$; according to the classification of Holtz and Gibbs (1956), this shale has a low degree of expansion.
The FSR ranged from 1.01 to 1.07 with an average of 1.06 , which indicates low expansivity according to the classification by Prakash and Sridharan (2004). The swell potential $\left(S_{\mathrm{p}}\right)$ from the

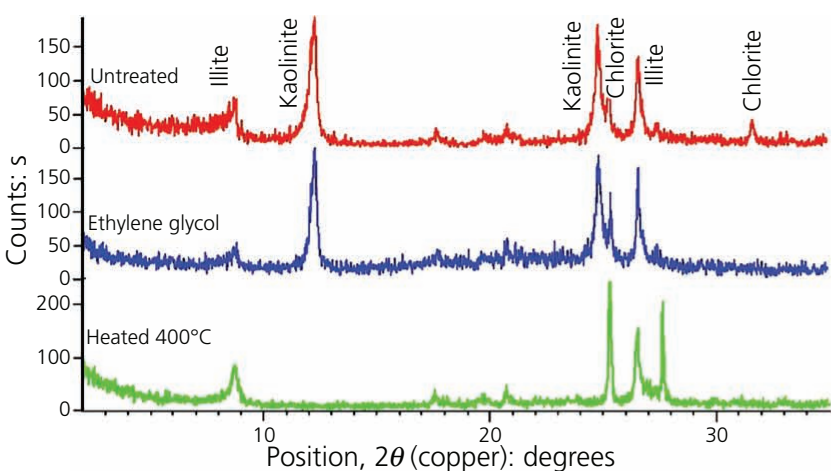

(a)

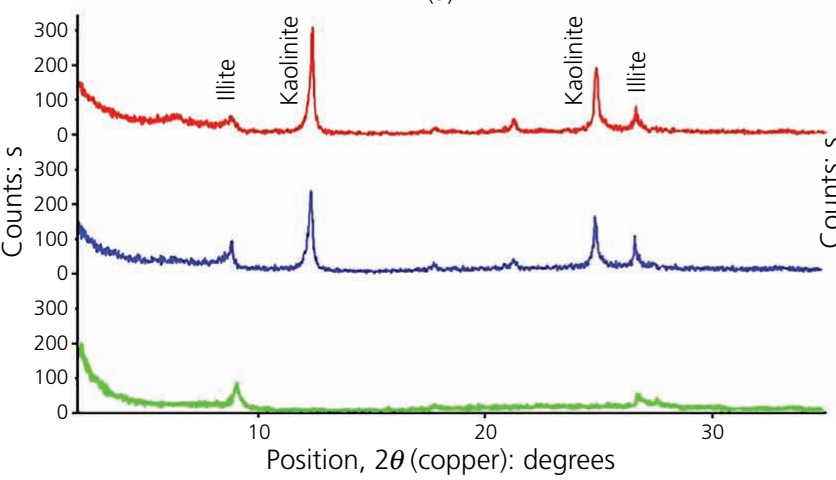

(c)

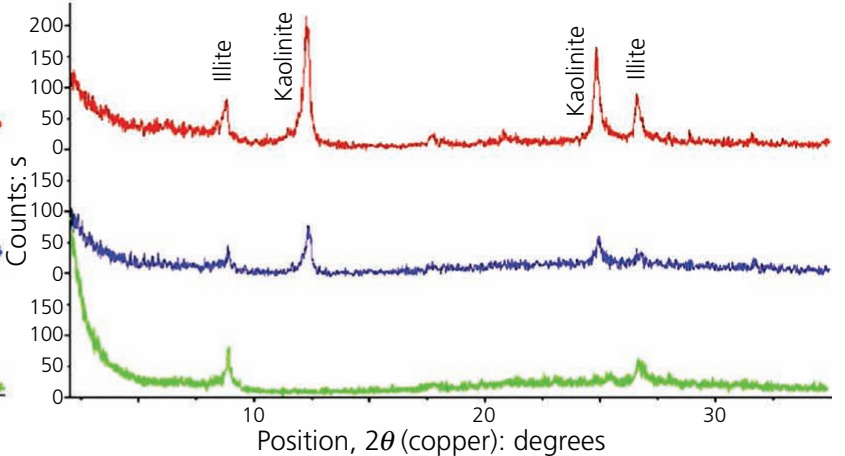

(b)

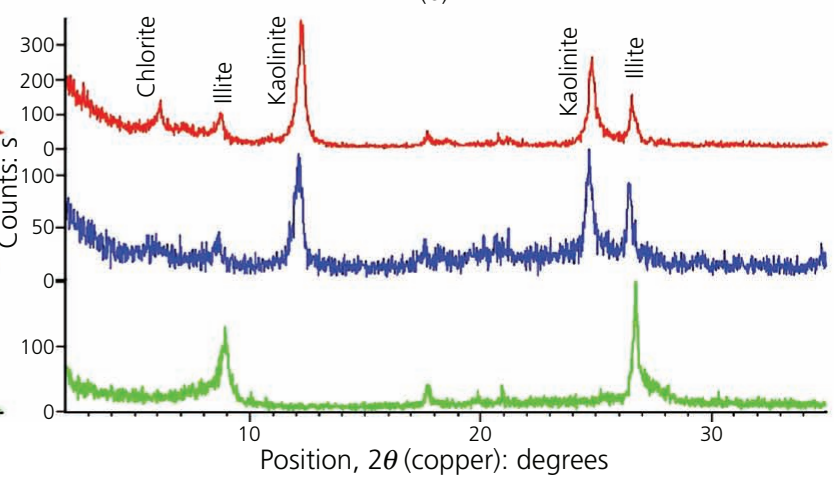

(d)

Figure 4. XRD patterns of clay mineral content in Tabuk shale samples: (a) $1.5 \mathrm{~m}$; (b) $3.0 \mathrm{~m}$; (c) 4 . ; (d) $6.0 \mathrm{~m}$ 
Impact of slaking shale behaviour on

damage of engineering structures, Saudi

Arabia

Embaby, Abu Halawa and Ramadan
1D oedometer of the shale was found to be quite low, ranging between 1.12 and $1.75 \%$ with an average of $1.50 \%$. According to Holtz and Gibbs (1956), it can be classified as having a low degree of expansion owing to the in situ conditions such as fissuring and slaking as well as the absence of expansive clay minerals such as montmorillonite and the presence of kaolinite and illite as dominant minerals.

Based on the results mentioned previously, Tabuk shale is light brown to light greyish in colour and is characterised as fissile, micaceous siltshale with a high void ratio, low PI, inactive clay

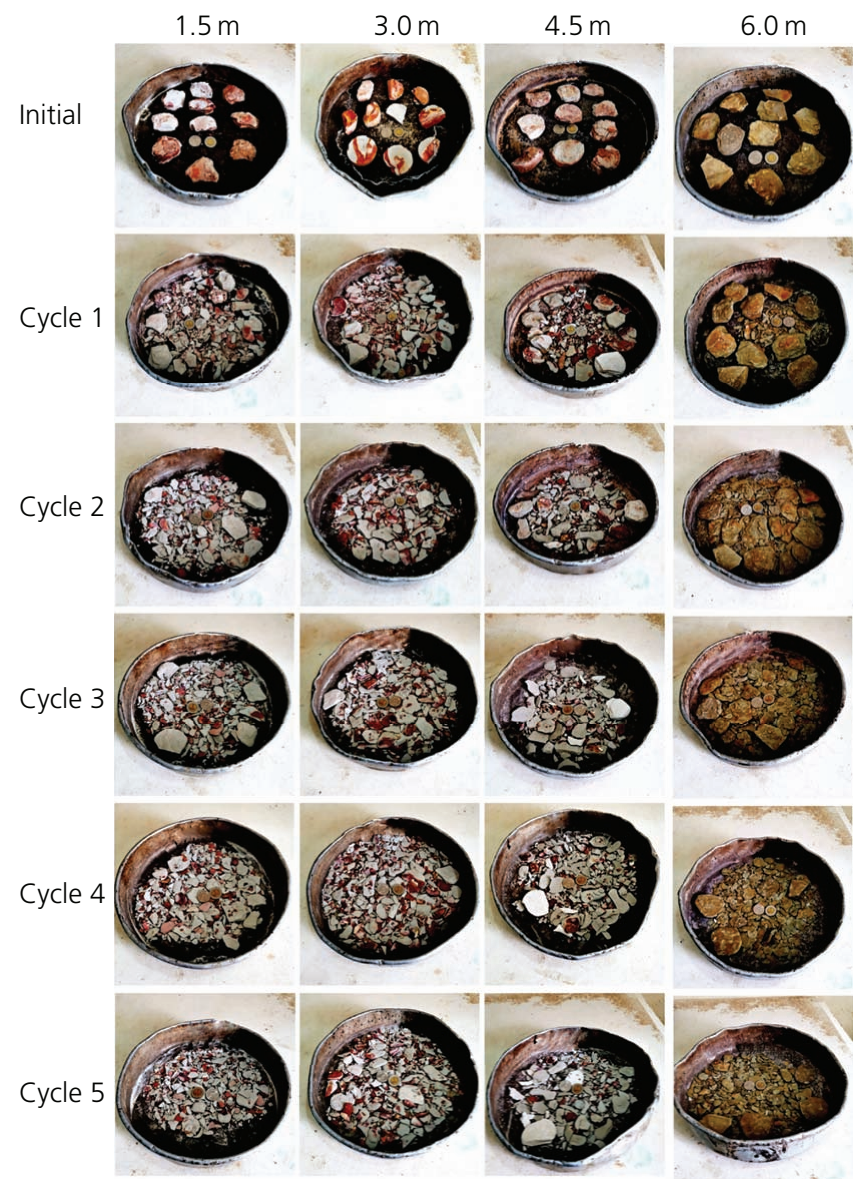

Figure 5. Slaking and disintegration of Tabuk shale fragments retained in the drum from the first to the fifth cycle during the dynamic slake durability test minerals, dominant non-expansive clay minerals and low swelling potential. As evidenced from the unique properties of this shale, the problems pertaining to buildings and infrastructures are not attributed to the expanded clay mineral content and were instead caused by other properties such as slaking resulting from drying and wetting cycles. This inference is supported by the slaking durability index $\left(I_{\mathrm{d}}\right)$ and the disintegration ratio $\left(D_{\mathrm{R}}\right)$, which were used to quantify the degree of slaking and to assess the durability of the shale.

\section{Slake durability index $\left(I_{\mathrm{d}}\right)$ and disintegration ratio $\left(D_{\mathrm{R}}\right)$ of shale}

Photographs of the Tabuk shale samples taken after each cycle of the dynamic slake durability test are presented in Figure 5. The shale fragments appeared to be broken into thin chips with roughly parallel tops and bottoms (Figure 5). According to the classification of ASTM D 4644 (ASTM, 2016g), the slaking behaviour of all shale samples after the second to fifth cycles of the slake durability test qualitatively belong to type II, with a mixture of large and small fragments.

The slake durability index $\left(I_{\mathrm{d}}\right)$, as determined according to ASTM D 4644 (ASTM, 2016g), and the disintegration ratio $\left(D_{\mathrm{R}}\right)$, as proposed by Erguler and Shakoor (2009), were used to quantify the degree of slaking and the durability of Tabuk shale. The results of $I_{\mathrm{d}}$ and $D_{\mathrm{R}}$ for each cycle of the slake durability test of the shale samples with depths are listed in Table 2. Generally, the disintegration of all shale samples increased with the number of cycles from the first to the fifth cycle, and the extent differed with depth.

The shale sample at a depth of $6 \mathrm{~m}$ showed $I_{\mathrm{d}}$ values as high as 85 and $66 \%$ after the second and the fifth cycles, respectively, whereas that at a depth of $1.5 \mathrm{~m}$ showed $I_{\mathrm{d}}$ values of $57 \%$ after the second cycle and $44 \%$ after the fifth cycle (Table 2). Shale samples at depths of 3.0 and $4.5 \mathrm{~m}$ exhibited moderate amounts of slaking, at 70 and $65 \%$ after the second cycle and 58 and $56 \%$ after the fifth cycle, respectively. The slake durability index values of the shale sample at $6 \mathrm{~m}$ were the highest through all five cycles, whereas that at a depth of $1.5 \mathrm{~m}$ was the lowest; the shale samples of both 3.0 and $4.5 \mathrm{~m}$ depths were intermediate (Figure 6).

All shale samples disintegrated into varied sizes of fragments after the slake durability test. The grain size distribution analysis of each shale fraction retained in the test drum after all five cycles was completed, as well as the particle size distribution curves.

Table 2. Slaking indices (\%) and disintegration ratios from five slaking test cycles of Tabuk shale

\begin{tabular}{|c|c|c|c|c|c|c|c|c|c|c|}
\hline \multirow{3}{*}{ Sample depth: $m$} & \multicolumn{10}{|c|}{ Values of slaking indices and disintegration ratio $\left(I_{\mathrm{d}}\right.$ and $\left.D_{\mathrm{R}}\right)$ for five cycles } \\
\hline & \multicolumn{2}{|c|}{ Cycle 1} & \multicolumn{2}{|c|}{ Cycle 2} & \multicolumn{2}{|c|}{ Cycle 3} & \multicolumn{2}{|c|}{ Cycle 4} & \multicolumn{2}{|c|}{ Cycle 5} \\
\hline & $I_{\mathrm{d} 1}$ & $D_{\mathrm{R} 1}$ & $I_{\mathrm{d} 2}$ & $D_{\mathrm{R} 2}$ & $I_{\mathrm{d} 3}$ & $D_{\mathrm{R} 3}$ & $I_{\mathrm{d} 4}$ & $D_{\mathrm{R} 4}$ & $I_{\mathrm{d} 5}$ & $D_{\mathrm{R} 5}$ \\
\hline 1.5 & 76 & 0.53 & 57 & 0.36 & 50 & 0.31 & 46 & 0.27 & 44 & 0.26 \\
\hline 3.0 & 75 & 0.59 & 70 & 0.47 & 66 & 0.43 & 63 & 0.39 & 58 & 0.36 \\
\hline 4.5 & 79 & 0.65 & 65 & 0.49 & 61 & 0.43 & 58 & 0.39 & 56 & 0.37 \\
\hline 6.0 & 94 & 0.91 & 85 & 0.76 & 77 & 0.64 & 71 & 0.53 & 66 & 0.48 \\
\hline
\end{tabular}


Impact of slaking shale behaviour on

damage of engineering structures, Saudi

Arabia

Embaby, Abu Halawa and Ramadan

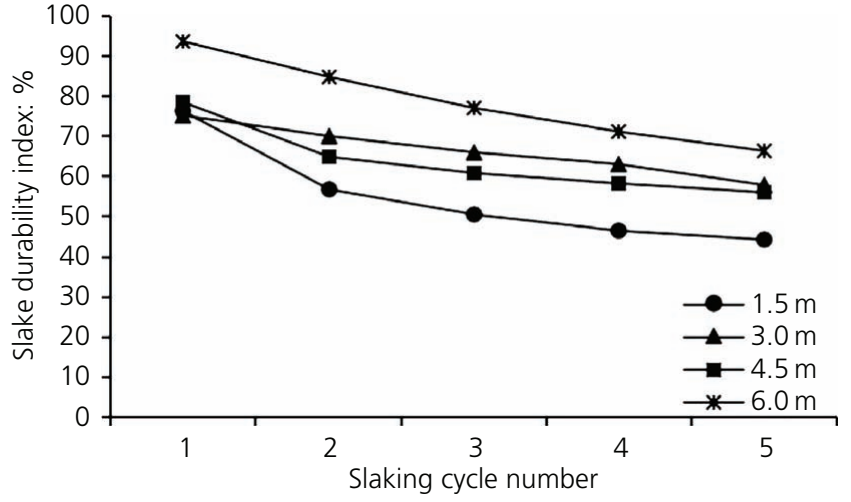

Figure 6. Slake durability index values of Tabuk shale samples at different depths through the five cycles of slake durability testing

These were used to determine the corresponding disintegration ratio $\left(D_{\mathrm{R}}\right)$. The results of the $D_{\mathrm{R}}$ of the shale samples obtained after all slaking cycles are listed in Table 2 and are presented in Figure 7.
Also, the disintegration ratio $\left(D_{\mathrm{R}}\right)$ of the shale samples at all depths exhibits the same results of the slake durability test, where the shale sample at a depth of $6 \mathrm{~m}$ had high $D_{\mathrm{R}}$ values across all five cycles. However, the shale sample at $1.5 \mathrm{~m}$ depth had the lowest $D_{\mathrm{R}}$ values, exhibiting a value of 0.53 after the first cycle and 0.26 after the fifth cycle of the test (Table 2 and Figure 7). The shale at depths of 3.0 and $4.5 \mathrm{~m}$ had nearly the same disintegration ratio as that after the first cycle (Figure 8). The coefficient relations $\left(R^{2}\right)$ between the $I_{\mathrm{d}}$ and $D_{\mathrm{R}}$ from the second and fifth cycles were 0.96 and 0.93 , respectively (Figure 9). The relation was stronger after the fifth cycle than that after the second cycle. In addition, the $R^{2}$ values of the relationship between the $I_{\mathrm{d}}$ and $D_{\mathrm{R}}$ for the slake durability test for all cycles revealed stronger values for the second and fifth cycles (Table 3). Therefore, both the second and fifth cycles of the slaking dynamic durability tests are considered the most appropriate for the assessment and classification of shale durability.

\section{Durability classification of shale}

In the current study, although the $I_{\mathrm{d} 5}$ data are more reliable than those of $I_{\mathrm{d} 2}$, the latter value was used to classify and assess the

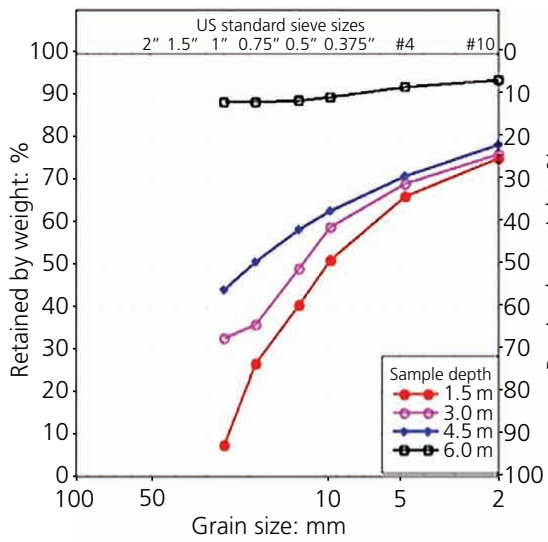

(a)

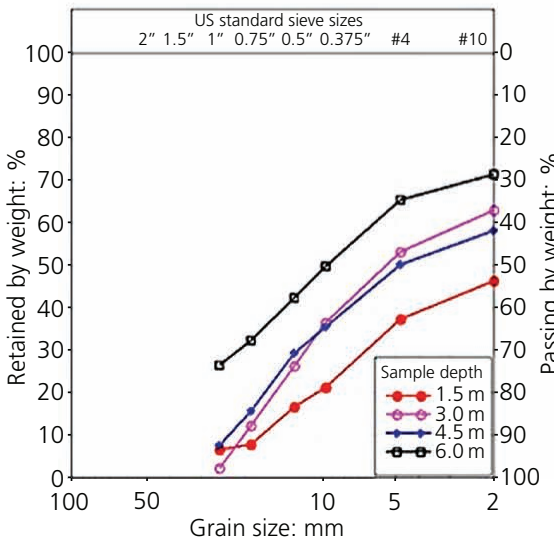

(d)

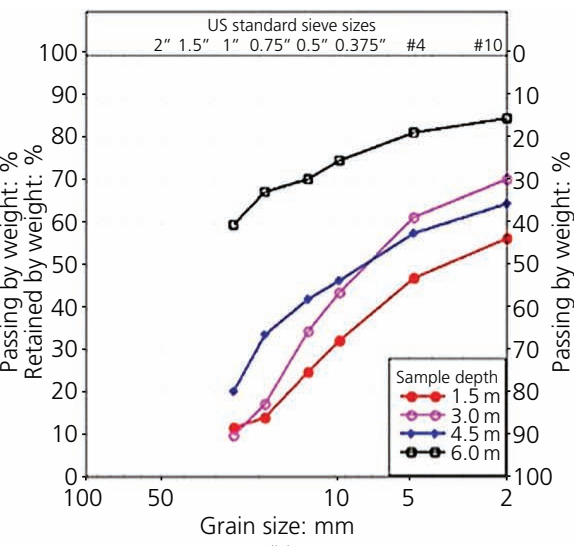

(b)

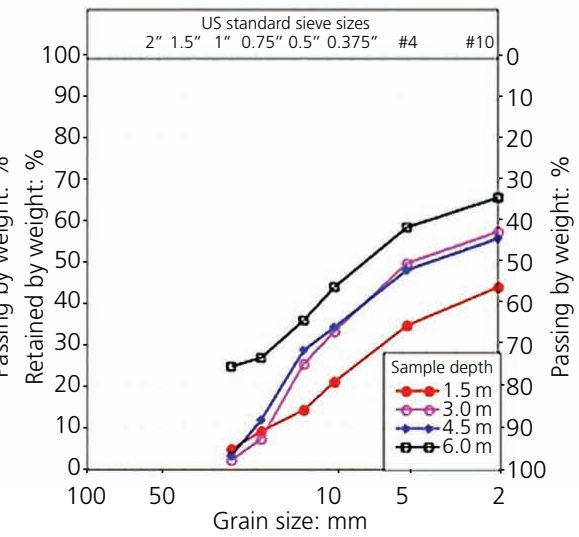

(e)

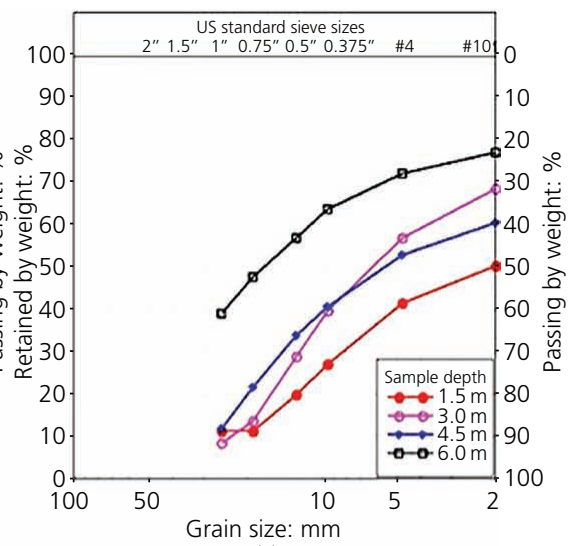

(c)

Figure 7. Particle size distribution curves of Tabuk shale samples at different depths, after all the cycles of slake durability tests: (a) cycle 1; (b) cycle 2; (c) cycle 3; (d) cycle 4; (e) cycle 5. 1" = 1 inch $=25.4 \mathrm{~mm}$ 
Impact of slaking shale behaviour on

damage of engineering structures, Saudi

Arabia

Embaby, Abu Halawa and Ramadan

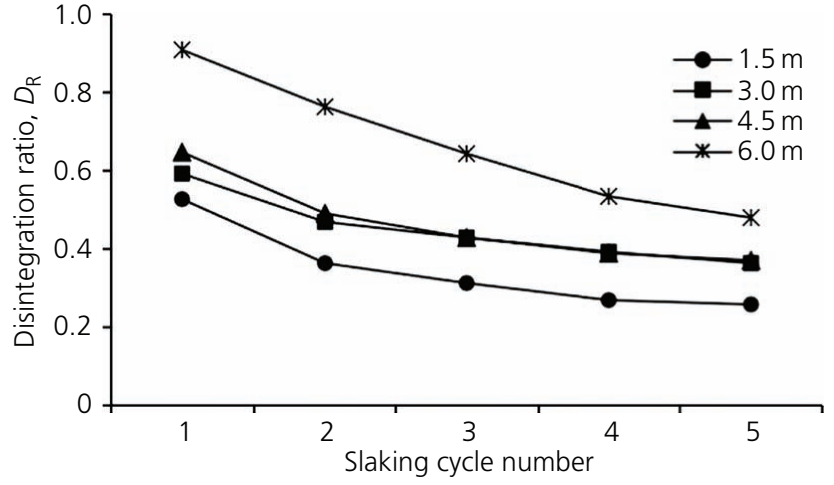

Figure 8. Disintegration ratio $\left(D_{R}\right)$ index of Tabuk shale plotted against the number of slaking cycles

durability of the shale, as recommended by the standards of ASTM D 4644 (ASTM, 2016g) and ISRM (2007).

\section{Classification based on $I_{\mathrm{d} 2}$ index}

Figure 10 presents a comparison of the slake durability classifications of Tabuk shale at various depths based on the $I_{\mathrm{d} 2}$ values given by Gamble (1971), Dick et al. (1994) and Gautam (2012). The shale sample at a depth of $1.5 \mathrm{~m}\left(I_{\mathrm{d} 2} 57 \%\right)$ was classified as low durable according to Gamble (1971) $\left(I_{\mathrm{d} 2}<60 \%\right)$ and Gautam (2012) $\left(I_{\mathrm{d} 2}<70 \%\right)$ and that at a depth of $4.5 \mathrm{~m}\left(I_{\mathrm{d} 2}\right.$ $65 \%$ ) was classified as low durable according to the classification by Gautam (2012) (Figure 10). The shale at depths of 6 and $3 \mathrm{~m}$ was classified as medium durable based on the values given by the three authors. However, all shale samples were classified as medium durable $\left(I_{\mathrm{d} 2} 50-70 \%\right)$ according to the classification by Dick et al. (1994) (Figure 10). A comparison of Table 2 and Figure 10 reveals that, generally, Tabuk shale has a slake durability index $\left(I_{\mathrm{d} 2}\right)$ of $57-85 \%$ and is classified as low to medium durability. All shale samples after the fifth cycle $\left(I_{\mathrm{d} 5}\right)$ of the slaking test $\left(I_{\mathrm{d} 5}<60 \%\right)$ fall within the low-durability range except for the shale sample at a depth of $6 \mathrm{~m}$ ranking in the medium range. Tabuk shale can be classified as low durability $\left(I_{\mathrm{d} 5}\right.$ $<60 \%$ ) according to the classification by Gamble (1971).

\section{Durability-plasticity classification}

The durability-plasticity classification developed by Gamble (1971) and recommended by ISRM (2007) is based on $I_{\mathrm{d} 2}$ and PI index values. Figure 11 presents the durability classification of Tabuk shale. Shale samples at depths of $1.5,3.0$ and $4.5 \mathrm{~m}$ fell within the medium-PI zone; and those at depths of 3.0 and $4.5 \mathrm{~m}$ fell within the medium-durability zone; and that at a depth of $1.5 \mathrm{~m}$ ranked in the low-durability zone. In contrast, the shale sample at a depth of $6 \mathrm{~m}$ fell within the low-PI and mediumdurability zone. Generally, an increase in the PI resulted in a decrease in the durability of the shale.

\section{Deo classification}

Based on slake durability tests $I_{\mathrm{d} 1}$ and $I_{\mathrm{d} 2}$, the classification by Deo (1972) for shale shows $I_{\mathrm{d} 2}<90 \%$ as soil-like, whereas $I_{\mathrm{d} 2}>$ $90 \%$ is classified as rock-like. The Deo classification is capable of

Table 3. $R^{2}$ values for the relationship between slake durability index $\left(I_{d}\right)$ and disintegration ratio $\left(D_{R}\right)$ after each cycle of the slake durability test for Tabuk shale, Tabuk, KSA

\begin{tabular}{lccccc} 
Disintegration ratio $\left(D_{\mathrm{R}}\right)$ for all & \multicolumn{4}{c}{$\begin{array}{c}\text { Slake durability index }\left(I_{\mathrm{d}}\right) \\
\text { cycles }\end{array}$} & \multicolumn{5}{c}{\begin{tabular}{c} 
for all cycles \\
\cline { 2 - 6 }
\end{tabular}} & $I_{\mathrm{d} 1}$ & $I_{\mathrm{d} 2}$ & $I_{\mathrm{d} 3}$ & $I_{\mathrm{d} 4}$ & $I_{\mathrm{d} 5}$ \\
\hline$D_{\mathrm{R} 1}$ & 0.96 & 0.85 & 0.67 & 0.70 & 0.74 \\
$D_{\mathrm{R} 2}$ & 0.90 & 0.93 & 0.78 & 0.81 & 0.83 \\
$D_{\mathrm{R} 3}$ & 0.84 & 0.96 & 0.87 & 0.88 & 0.90 \\
$D_{\mathrm{R} 4}$ & 0.74 & 0.95 & 0.91 & 0.94 & 0.96 \\
$D_{\mathrm{R} 5}$ & 0.73 & 0.93 & 0.89 & 0.92 & 0.96
\end{tabular}

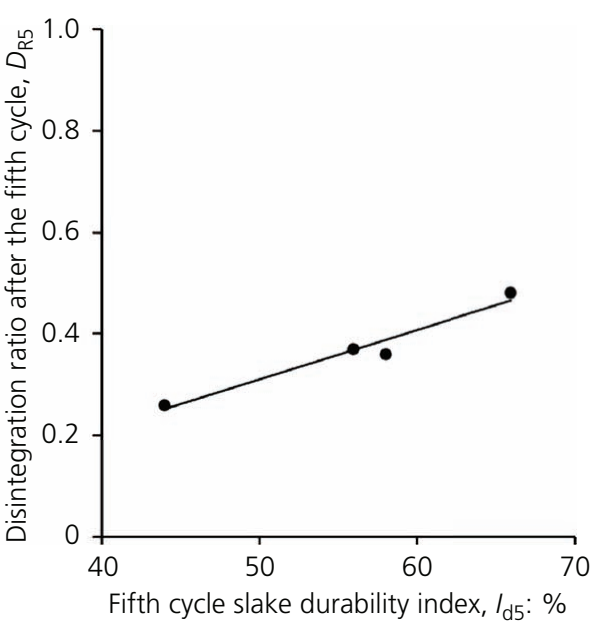

(b)

Figure 9. Relationship between the slake durability index and the disintegration ratio of Tabuk shale after the (a) second cycle and (b) fifth cycle tests 


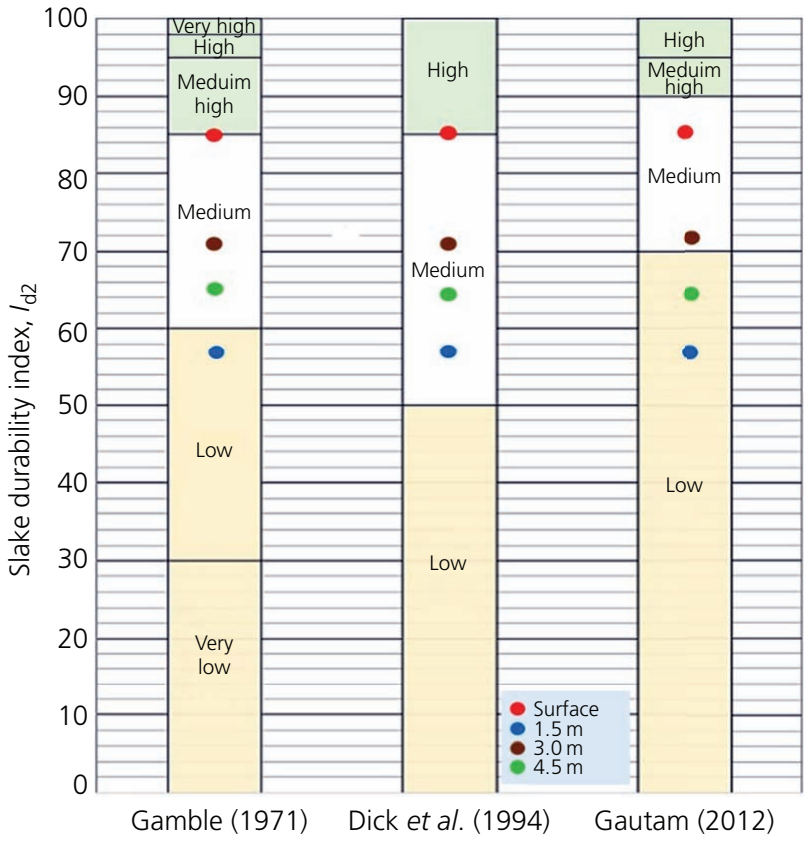

Figure 10. Slake durability classification of Tabuk shale according to depth based on the durability index of the second cycle $\left(I_{\mathrm{d} 2}\right)$ according to the classifications of Gamble (1971), Dick et al. (1994) and Gautam (2012)

predicting the behaviour of shale in the long term. All Tabuk shale samples have $I_{\mathrm{d} 2}<90 \%$ (Table 2); thus, according to the classification by Deo (1972), Tabuk shale is soil-like.

\section{Shale rating classification}

The shale rating classification by Franklin (1981) includes three index properties - namely, the slake durability index $\left(I_{\mathrm{d} 2}\right)$, point-load

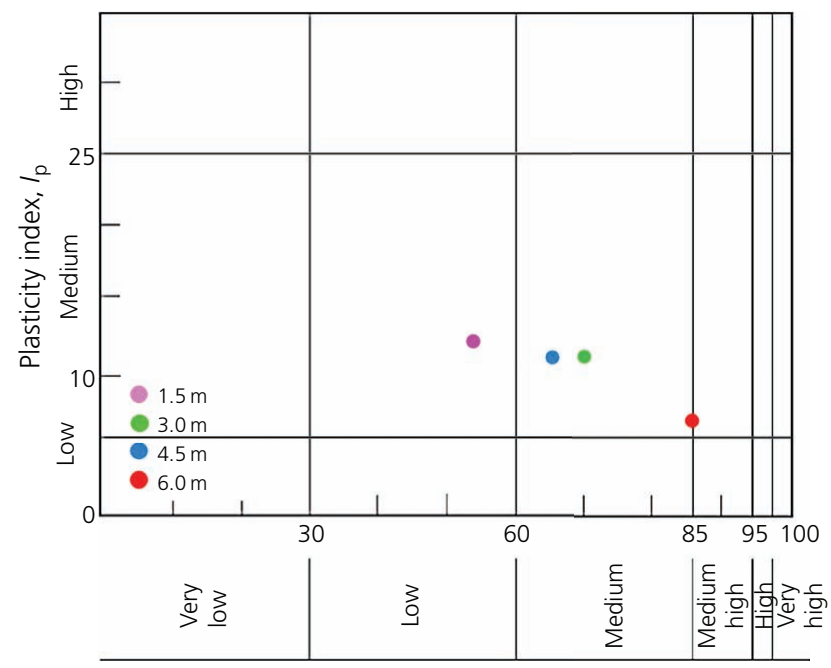

Second cycle slake durability, $I_{\mathrm{d} 2}: \%$

Figure 11. Classification of Tabuk shale based on the geotechnical classification by Gamble (1971) index $\left(I_{\mathrm{s} 50}\right)$ and PI - plotted on one graph (Figure 12). The pointload index is used to classify durable shale at the limit $I_{\mathrm{d} 2}>80 \%$, and the PI is applied for $I_{\mathrm{d} 2}<80 \%$. The shale rating ranges from 0 to 9 , indicating the lowest to highest durability, respectively. Shales with $I_{\mathrm{d} 2}<80 \%$ are classified as soil-like, whereas those with $I_{\mathrm{d} 2}>$ $80 \%$ are classified as rock-like. Soil-like shales are subjected to the Atterberg limits test to determine the PI, whereas rock-like shales are subjected to point-load strength tests to determine their strength (Franklin and Dusseault, 1989). Plotting the values of $I_{\mathrm{d} 2}$, PI and $I_{\mathrm{s} 50}$ of Tabuk shale on the shale rating diagram (Figure 12) developed by Franklin (1981) revealed that samples at depths of 1.5, 3.0 and $4.5 \mathrm{~m}$ were spread throughout an area described as soil-like with a nonplastic nature, whereas the shale sample at a depth of $6 \mathrm{~m}$ fell in shale rating zone 6 , which is classified as rock-like.

\section{Disintegration ratio classification}

The $D_{\mathrm{R}}$ value distinguishes between the high and low durability of rocks. The index ranges from 0 to 1 , with low values indicating less durable rock and high values indicating high-durability rock. The classification of Tabuk shale according to the proposed classification of Erguler and Shakoor (2009) after the second cycle test is listed in Table 4. Figure 13 presents the $D_{\mathrm{R}}$ values of Tabuk shale for the five cycles of the slaking test, with the boundaries of classification following the $D_{\mathrm{R}}$ classification by Erguler and Shakoor (2009). The subsurface Tabuk shale samples after the second cycle until the fifth cycle were classified as low to medium durability. However, the shale sample at a depth of $6 \mathrm{~m}$ after the second cycle to the fourth cycle was classified as medium durability but showed low durability after the fifth cycle. According to the $D_{\mathrm{R}}$ classification, Tabuk shale is classified as low to medium durability.

\section{Fabric/texture of shale}

The fabric of Tabuk shale samples was clearly observed by SEM. Using the microstructural classification system proposed by Moon and Beattie (1995) and Koralegedara and Maynard (2017), Tabuk shale can be categorised based on their macrofabric into laminated shale type. Two types of microfabric, matrix and laminar fabrics, were observed among Tabuk shale samples (Figure 14). Characteristics observed by using scanning electronic microscopic images evinced both edge-face and face-face contacts between clay flakes, relatively numerous microcracks and void ratio. The shale at all depths analysed had similar fabrics. Various other fabrics and particle shapes were observed over the samples including crystal growth of gypsum and salts in the microcracks and between the bedding planes of shale (Figure 14). The durability of shales in different localities can be attributed to their textural properties (Russell, 1982). The matrix and laminar fabrics increased the void ratio in shale. The durability of Tabuk shale can be significantly related to the void ratio and permeability created by the different types of fabrics.

\section{Discussion}

Tabuk shale is silt-sized and fissile with a low PI, inactive clay, a lack of expanding clay minerals such as montmorillonite and low swelling potential. All of these characteristics indicate that the 


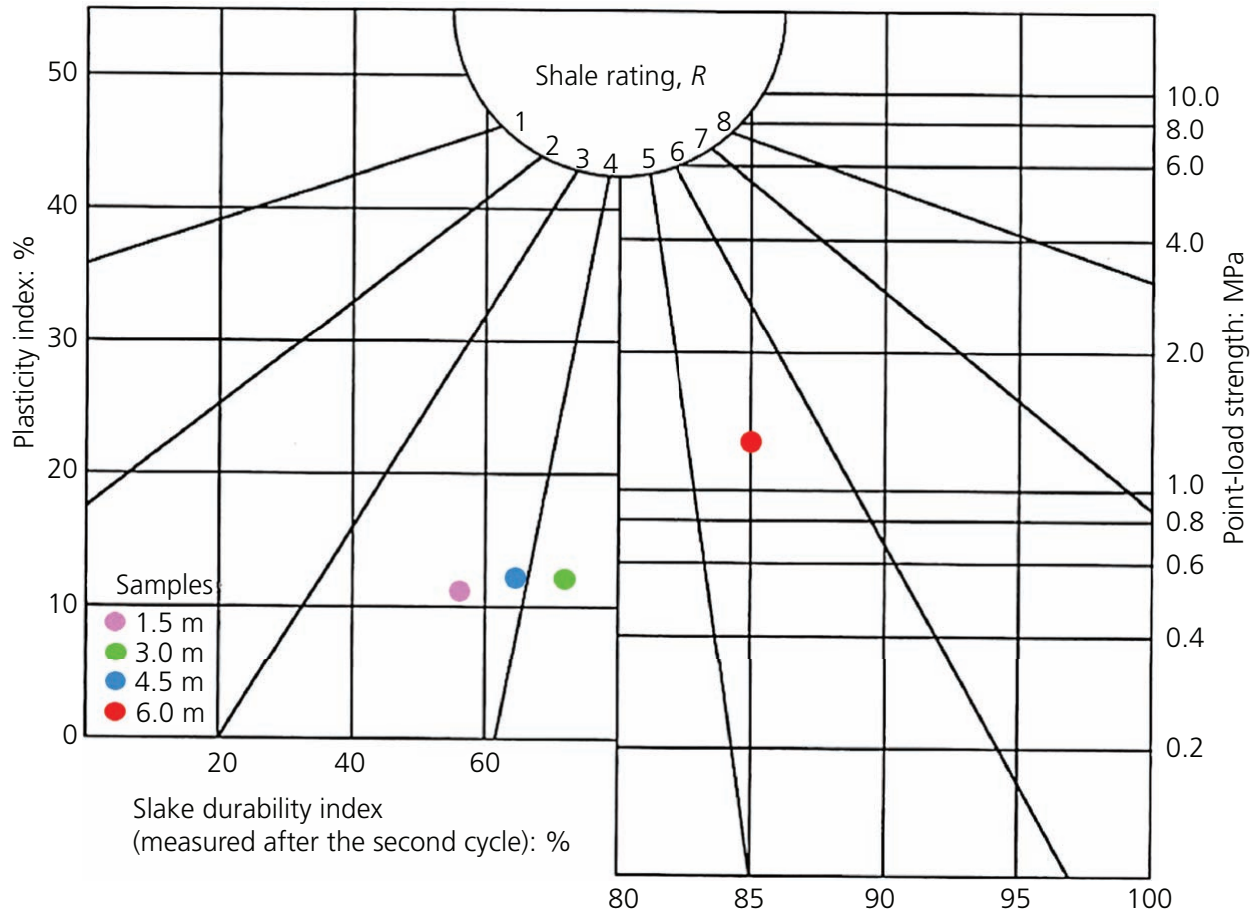

Figure 12. Classification of Tabuk shale based on shale ratings proposed by Franklin (1981)

geotechnical problems owing to expansion of clay minerals are negligible in this shale. However, the buildings and constructions built on the shale succession exhibit significant amounts of deformation, which are attributed to other properties such as durability and slaking of the shale.

The slaking phenomenon is prevalent in northern Tabuk districts including Al-Qadisyah, Al-Masif, Al Nakhil, Arrwdah and Al Nahdah, where Ra'an Shale layers are exposed or are close to the ground surface. Tabuk shale has a low-to-medium slake durability index and low disintegration ratios; hence, it crumbles into small, soft fragments. Although shale at a depth of $1.5 \mathrm{~m}$ showed the highest occurrence of slaking phenomena and is classified as soillike, this depth is most often used for foundations of buildings and infrastructure placement.

Table 4. Disintegration ratio classification of Tabuk shale based on the classification by Erguler and Shakoor (2009)

$\begin{array}{lcc}\begin{array}{l}\text { Durability classification } \\ \text { (Erguler and Shakoor, } \\ \text { 2009) }\end{array} & \begin{array}{c}\text { Disintegration ratio } \\ \left(\boldsymbol{D}_{\mathrm{R}}\right) \text { after the second } \\ \text { cycle test }\end{array} & \begin{array}{c}\text { Examined } \\ \text { shale } \\ \text { samples }\end{array} \\ \begin{array}{l}\text { Very low } \\ \text { Low }\end{array} & 0.00-0.19 & - \\ & 0.20-0.49 & \begin{array}{c}1.5,3 \text { and } \\ 4.5 \mathrm{~m} \\ \text { depths }\end{array} \\ \text { Medium } & 0.50-0.78 & 6 \mathrm{~m} \text { depth } \\ \text { Medium high } & 0.79-0.91 & - \\ \text { High } & 0.92-0.95 & - \\ \text { Very high } & 0.96-1.00 & -\end{array}$

The slaking of Tabuk shale is likely caused by one or a combination of the following mechanisms: pore-air compression (PAC), negative pore pressure, stress created or depleted from precipitation or dissolution of minerals by perched groundwater and cracking caused by differential stress after drying and shrinkage. Vallejo et al. (1993) and many other researchers proposed a slaking mechanism in terms of PAC. Tabuk City has distinct wet and dry periods throughout the year and is situated in an arid climate region. In the wet period, higher rainfall rates occur in a short time, whereas the evaporation rate is very high in the dry period. Shale situated at shallow depths during a drying cycle with an intense evaporation rate is extremely desiccated, and the bulk of the voids in the shale may become filled with air. On rapid wetting by suddenly higher rainfall rates (flooding) or the accidental flow of water from pipe leakage, the air is captured, and its pressure increases in the internal voids. This entrapped air exerts tension on the shale skeleton, causing local expansion and decreased strength. This in turn leads to disintegration into clayey soil by slaking of the shale along the weakest planes of lamination or fissility. This transformation of shale from rock-like to soil-like often leads to settlement and shear failure. The PAC mechanism is expected to be the most significant slaking phenomenon of the subsurface shale layers and can lead to defects in building foundations and infrastructures. Vallejo et al. (1993) mentioned that PAC is the predominant slaking mechanism in shale composed primarily of non-expansive clay minerals such as kaolinite and, to a less degree, illite. Tabuk shale contains nonswelling clay minerals, particularly kaolinite; therefore, PAC might be a vital slaking mechanism of shale. 


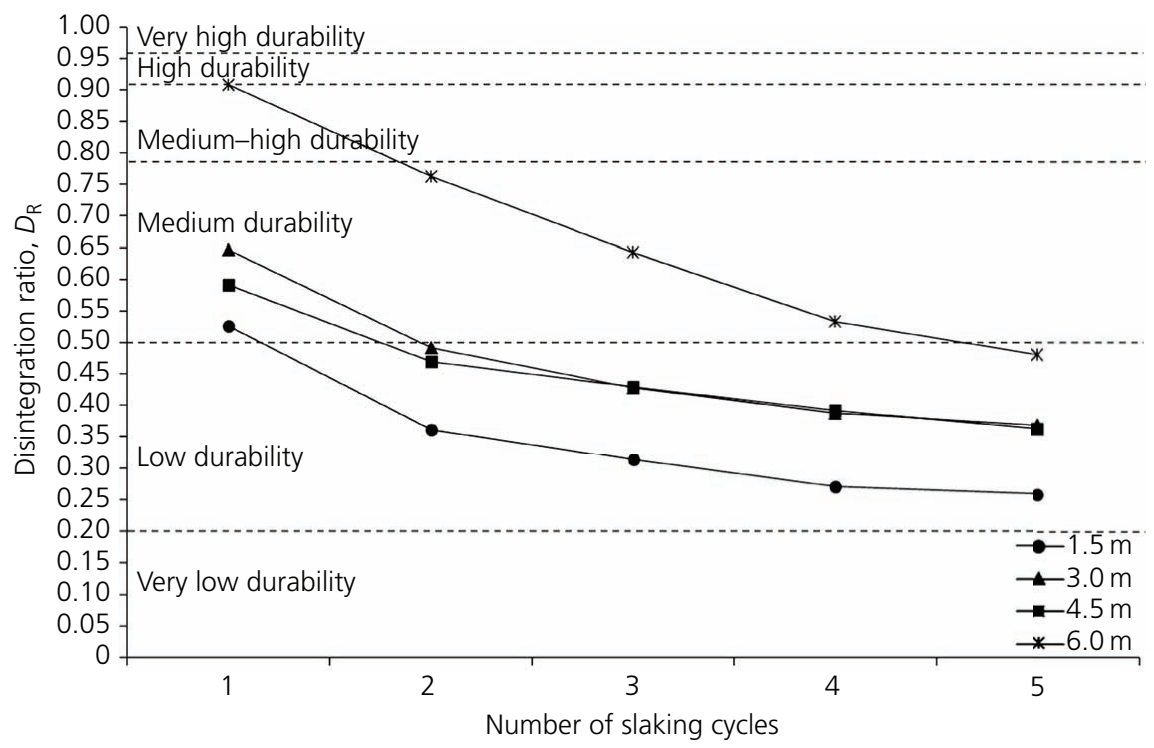

Figure 13. Slake durability classification based on the disintegration ratio $\left(D_{R}\right)$ after five cycles of testing. That after the second cycle test was determined following the paper by Erguler and Shakoor (2009)

Negative pore pressure exists when the free energy of the pore water is less than that of water under atmospheric pressure (Mitchell, 1976). The wetting and drying cycles occurring at the ground surface can be considered as pressure cycles as a consequence of the negative pore pressure generated by desiccation (Grice, 1968). Water exerting negative pore pressure exists in a state of tension and exerts stress on the structure of the material and consequent tensile failure of weak intercrystalline bonds. In Tabuk shale, the negative pore pressure mechanism is expected to be significant in layers below the ground surface owing to oscillation in MC zones. The loss of free water during desiccation (drying cycle) of Tabuk shale causes an increase in negative pore pressure through internal suction stress and can lead to slaking and tensile failure of the shale.

The texture, fabric and mineralogical composition of argillaceous rocks are important parameters controlling their durability (Bryson et al. 2019; Corominas et al., 2015; Gautam and Shakoor, 2017; Koralegedara and Maynard, 2017; Russell, 1982). Tabuk shale contains $92 \%$ fine-grained constituents including $57.6 \%$ silt and $34.4 \%$ clay, and its matrix consists of phyllosilicate minerals, including clay minerals and micaceous minerals. In addition, it has a heterogeneous muddy texture with a small amount of cement. This shale is fissile with a finely laminated structure, and microcracks exist parallel to the lamination. Bonds are present between grains of the clastic framework, those of phyllosilicate minerals or both. Its efficiency depends on the amount of the matrix and mainly on the content of phyllosilicate minerals (Corominas et al., 2015). Accordingly, the increase in matrix content and the presence of micaceous minerals in Tabuk shale make the bonding weak, which causes the sheets of the phyllosilicate minerals to split apart through exfoliation, resulting in disintegration of the shale. The microstructures stimulate the infiltration and evaporation of water through wetting and drying cycles with the subsequent crystal growth of calcium sulfate $\left(\mathrm{CaSO}_{4} \cdot 2 \mathrm{H}_{2} \mathrm{O}\right)$ and halite $(\mathrm{NaCl})$, which was confirmed by SEM. These crystals likely have an impact on the formation of cracks - that is, the crystal growth causes an increase in the opening of the microcracks, which generates discontinuity planes and degradation of the shale. This results in slaking, which increases the fissility of the shale and vice versa by partial dissolution of the salt minerals along the laminations during the wetting cycle or expansion owing to the growth of minerals between the laminations during the drying cycle. The SEM results indicate that the development of gypsum crystals could be a crucial factor in the degradation because their presence interrupts the structure and breaks down the diagenetic bonds of the shale.

As the voids and microcracks of shale increase, its permeability increases, and the shale tends to break easily when interacting with water. Hence, Tabuk shale, with matrix and laminar fabrics, is less durable and is subject to rapid disintegration. The mineralogical constituents, texture (grain or matrix), structure and fabric are critical parameters exerting substantial control over the durability of this shale. Moreover, they profoundly affect the slaking processes, which changes the intrinsic characteristics of the shale and leads to particle cohesion and the creation of microcracks and fissures. The slake durability of mudrocks is closely related to the rock fabric, as expressed by void ratio and absorption (Dick and Shakoor, 1994). The reduction in the resistance of Tabuk shale is caused by changes in the shale structure and the development of microfissures and voids caused by the growth or dissolution of gypsum and halite minerals. This process leads to an increase in the void ratio and indicates that as 
Impact of slaking shale behaviour on

damage of engineering structures, Saudi

Arabia

Embaby, Abu Halawa and Ramadan
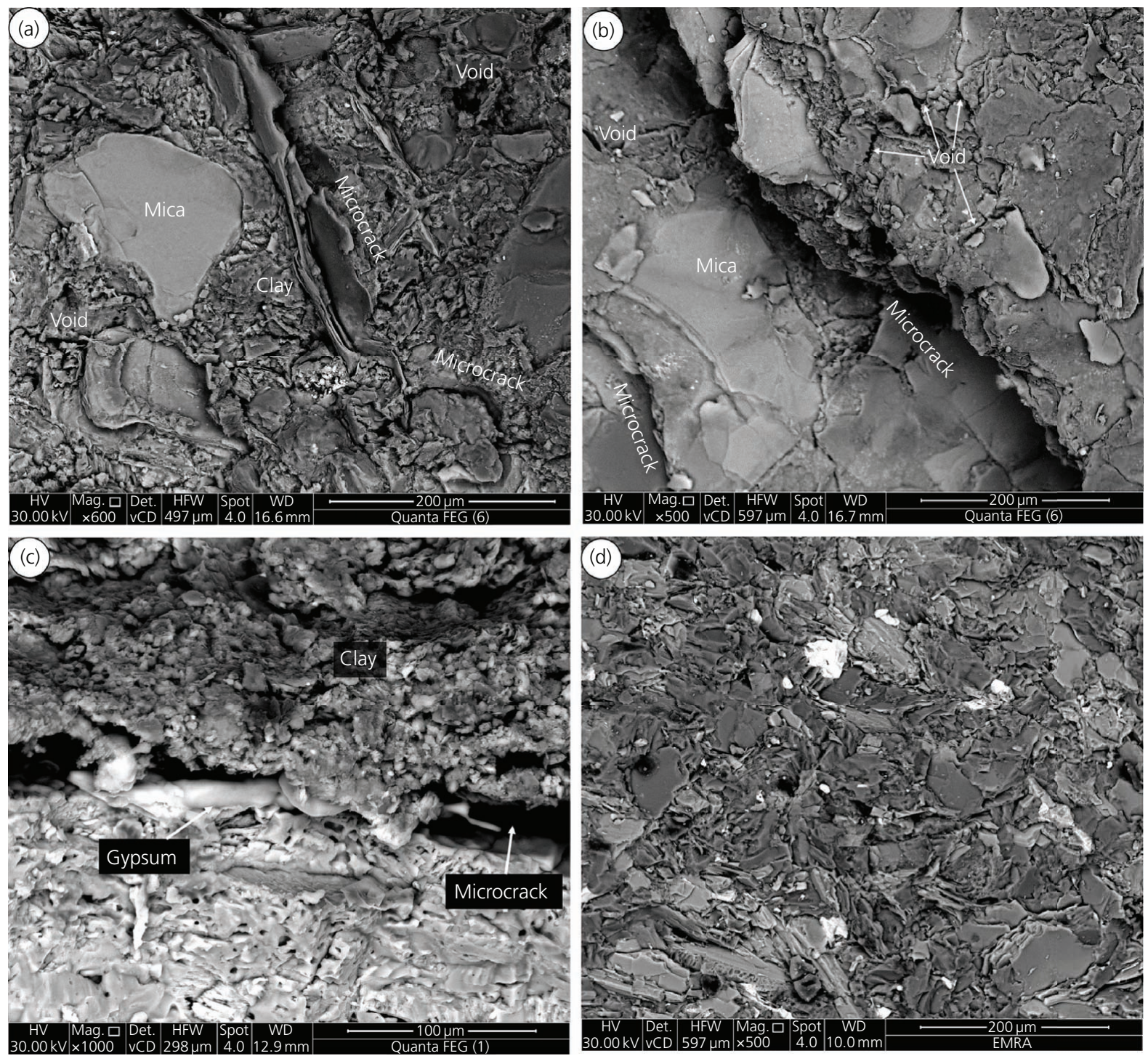

Figure 14. SEM images of Tabuk shale displaying (a) open randomly oriented fabric with microcracks and many voids, (b) microcracks on the laminar plane, (c) microcracks and voids filled with gypsum and halite minerals and (d) open randomly oriented fabric

shale slaking occurs, its structure becomes more open, and the resistance decreases during the application of shear stress.

Slaking and durability are vital physical characteristics of Tabuk shale. This shale is highly susceptible to the weathering process and tends to slake and crumble into softened materials when immersed or contacting with water. This causes disintegration and strength reduction of the shale. Regarding these tendencies, Dewhurst et al. (1998) and Broichhausen et al. (2005) stated that the mechanical behaviour of shale can change dramatically, with $40-80 \%$ reduction in shear strength occurring over periods of 2-70 years. The slaking phenomenon causes a transition in Tabuk shale from rock-like to soil-like. As a result, the stiffness and strength are lowered, which leads to instability and causes severe damage problems within building foundations and infrastructures.

\section{Conclusion}

The essential goal of this research is to establish the role of the slake durability of Ra'an Shale on geotechnical problems that have caused severe deformation within foundations of building and infrastructure in Tabuk City. Quantitative indices were used to evaluate the variations in the behaviour of the shale. The major conclusions of this study are given as follows.

The slaking behaviours of Tabuk shale and its transitional state from rock to soil often are accompanied by a reduction in shear strength. The damage to buildings and infrastructure is not related 
to the expansion of clay minerals within the shale. Rather, they are influenced significantly by the slaking of shale and its transitional behaviour from rock-like to soil-like.

Tabuk shale has a low-to-medium slake durability index and low disintegration ratios; thus, it is classified as soil-like. It crumbles into small, softened fragments when subjected to cycles of wetting and drying. The mechanical behaviour dramatically reduces with time, showing a quick transitional behaviour from rock-like to soil-like, which involves reductions in shear strength over a short period. Shale at a depth of $1.5 \mathrm{~m}$ has lower durability than that at other depths. Therefore, it is unsuitable for foundations of building or road construction and should be replaced by suitable, durable materials.

The PAC and crystal growth or dissolution of sulfate and halite minerals are significant slaking mechanisms. These processes trigger the disintegration of Tabuk shale because they interrupt the structure and destroy the diagenetic bonds of the shale, leading to reductions in shear strength and causing heaving and settlement of structures.

The assessment of shale durability is not dependent only on the slaking index values or the disintegration ratio. Rather, it depends on a combination of sedimentological and geotechnical parameters such as the void ratio; texture; fabric; content of soluble minerals; compressive strength or the bond strength of the matrix; amount and type of cement; and geological history. These parameters should be considered in the durability classification of shale; thus, further analysis and development is required.

Precautions should be considered when planning construction on shale, and its fragments should be avoided as construction fill or pavement materials owing to its rapid disintegration. The walls of excavation tunnels should be lined immediately, and excavation infrastructure such as extending network pipes in this shale should be completed and backfilled without delay. Most importantly, geotechnical engineers should handle slaked shale as soil rather than rock.

\section{Acknowledgements}

The authors are greatly indebted to Professor Dr Ahmed Basal, head of the Geology Department, Faculty of Science, Damietta University, for offering long-standing collaboration and fruitful scientific discussion. In addition, thanks are extended to Dr Abed El Kareem El Rosttum and Hikmat El Rosttum, owners of Soil \& Foundation Co. and Geotechnical \& Environmental Co., KSA, respectively, for providing the laboratory facility for conducting the geotechnical tests in this work.

\section{REFERENCES}

Abdulkarim A, Gaber AFD, Youssef AM and Pradhan B (2019) Flood hazard assessment of the urban area of Tabuk City, Kingdom of Saudi Arabia by integrating spatial-based hydrologic and hydrodynamic modelling. Sensors 19(5): article 1024, https://doi.org/10.3390/ s19051024.
ASTM (2016a) D 854: Standard test methods for specific gravity of soil solids by water pycnometer. ASTM International, West Conshohocken, PA, USA.

ASTM (2016b) D 2216: Standard test methods for laboratory determination of water (moisture) content of soil and rock by mass. ASTM International, West Conshohocken, PA, USA.

ASTM (2016c) D 422: Standard test method for particle - size analysis of soils. ASTM International, West Conshohocken, PA, USA.

ASTM (2016d) D 4318: Standard test method for liquid limit, plastic limit, and plasticity index of soils. ASTM International, West Conshohocken, PA, USA.

ASTM (2016e) D 4546: Standard test methods for one-dimensional swell or collapse of soils. ASTM International, West Conshohocken, PA, USA.

ASTM (2016f) D 5731: Standard test method for determination of the point load strength index of rock and application to rock strength classifications. ASTM International, West Conshohocken, PA, USA

ASTM (2016g) D 4644-08: Standard test method for slake durability of shales and similar weak rocks. ASTM International, West Conshohocken, PA, USA.

Berisavljević Z, Berisavljević D, Rakić D and Radić Z (2018) Application of geological strength index for characterization of weathering induced failures. Građevinar 70(10): 891-903, https://doi.org/10.14256/JCE. 1876.2016.

Broichhausen H, Littke R and Hantschel T (2005) Mudstone compaction and its influence on overpressure generation, elucidated by a $3 \mathrm{D}$ case study in the North Sea. International Journal of Earth Sciences 94(5): 956-978, https://doi.org/10.1007/s00531-005-0014-1.

Bryson LS, Kirkendoll JS and Mahmoodabadi M (2019) A new rapid method to assess the durability of shale. Geotechnical and Geological Engineering 37(5): 4135-4150, https://doi.org/10.1007/s10706-019-00898-x.

Corominas J, Martinez-Bofill J and Soler A (2015) A textural classification of argillaceous rocks and their durability. Landslides 12(4): 669-687, https://doi.org/10.1007/s10346-014-0520-y.

Dafalla MA and Al-Shamrani MA (2012) Expansive soil properties in a semi-arid region. Research Journal of Environmental and Earth Sciences 4(11): 930-938.

Deo P (1972) Shales as Embankment Materials. Purdue University, West Lafayette, IN, USA. See https://docs.lib.purdue.edu/cgi/viewcontent. cgi? article $=2896 \&$ context $=$ jtrp $($ accessed 18/05/2020).

Dewhurst DN, Aplin AC, Sarda JP and Yang Y (1998) Compaction-driven evolution of porosity and permeability in natural mudstones: an experimental study. Journal of Geophysical Research: Solid Earth 103(B1): 651-661, https://doi.org/10.1029/97JB02540.

Dick JC, Shakoor A and Wells N (1994) Geological approach to-ward developing a mudrock durability classification system. Canadian Geotechnical Journal 31(1): 17-27, https://doi.org/10.1139/t94-003.

Embaby A, Abu Halawa A and Ramadan M (2017) Integrating geotechnical investigation with hydrological modelling for mitigation of expansive soil hazards in Tabuk City, Saudi Arabia. Open Journal Modern Hydrology 7(1): 11-37, https://doi.org/10.4236/ojmh.2017.

Erguler ZA and Shakoor A (2009) Quantification of fragment size distribution of clay-bearing rocks after slake durability testing. Environmental and Engineering Geoscience 15(2): 81-89, https://doi. org/10.2113/gseegeosci.15.2.81.

Franklin JA (1981) A shale rating system and tentative applications to shale performance. Transportation Research Record 790: 2-12, https:// doi.org/10.1016/0148-9062(82)91654-0.

Franklin JA and Dusseault MB (1989) Rock Engineering. McGraw-Hill Inc, New York, NY, USA.

Gamble JC (1971) Durability-Plasticity Classification of Shales and Other Argillaceous Rocks. PhD thesis, University of Illinois at Urbana Champaign, Champaign, IL, USA.

Gautam TP (2012) An Investigation of Disintegration Behavior of Mudrocks Based on Laboratory and Field Tests. PhD thesis, Kent State University, Kent, OH, USA. 
Gautam TP and Shakoor AA (2017) Durability classification of claybearing rocks based on particle size distribution of slaked material. Environmental and Engineering Geoscience 23(2): 125-136, https:// doi.org/10.2113/gseegeosci.23.2.125.

Grice RH (1968) The effect of temperature-humidity on the disintegration of non-expandable shales. Bulletin Associate Engineering Geology 5(2): 70-77.

Heidari M, Rafiei B, Mohebi Y and Rastegarian V (2016) Prediction of long-term slake durability of clay-bearing rocks. Geopersia $\mathbf{6 ( 1 )}$ : 35-43, https://doi.org/10.22059/jgeope.2016.57820.

Holtz WG and Gibbs HJ (1956) Engineering properties of expansive clays. Transactions of the American Society of Civil Engineers 121(1): 641-663.

ISRM (International Society for Rock Mechanics) (2007) The complete ISRM suggested methods for rock characterization, testing and monitoring: 1974-2006. In Suggested Methods Prepared by the Commission on Testing Methods (Ulusay R and Hudson JA (eds)). International Society Rock Mechanics, Ankara, Turkey, p. 628.

Kaminski MA, Perdana P, Abouelresh MO and Babalola L (2019) Late Ordovician agglutinated foraminifera from the Ra'an Shale Member, Qasim Formation of Saudi Arabia as indicators of the O40 Maximum Flooding Surface. Stratigraphy 16(1): 27-39, https://doi.org/10.29041/ strat.16.1.27-39.

Koncagul EC and Santi PM (1999) Predicting the unconfined compressive strength of the Breathitt shale using slake durability, shore hardness and rock structural properties. International Journal of Rock Mechanics and Mining Sciences 36(2): 139-153, https://doi.org/10. 1016/S0148-9062(98)00174-0.

Koralegedara NH and Maynard JB (2017) Chemical, mineralogical and textural properties of the Kope Formation mudstones: how they affect its durability. Engineering Geology 228: 312-322, https://doi.org/10. 1016/j.enggeo.2017.08.025.

Mitchell JK (1976) Fundamentals of Soil Behaviour, 1st edn. Wiley New York, NY, USA.

Moon VG and Beattie AG (1995) Textural and micro-structural influences on the durability of Waikato coal measures mudrocks. Quarterly Journal of Engineering Geology and Hydrogeology 28(3): 303-312, https://doi.org/10.1144/GSL.QJEGH.1995.028.P3.08.

Pettijohn FJ (1957) Sedimentary Rocks. Harper \& Row, New York, NY, USA.

Prakash K and Sridharan A (2004) Free swell ratio and clay mineralogy of fine-grained soils. Geotechnical Testing Journal 27(2): 220-225, https://doi.org/10.1520/GTJ10860.
Putera AMA, Pramusandi S and Damianto B (2017) Identification and classification of clayshale characteristic and some considerations for slope stability. African Journal Environmental Science and Technology 11(4): 163-197, https://doi.org/10.5897/AJEST2014. 1792.

Richardson DN (1985) Relative durability of shale - a suggested rating system, building on/with sedimentary bedrock. In Proceedings of the 36th Annual Highway Geology Symposium: Building on/with Sedimentary Bedrock (West TR (ed.)). Indiana Department of Highways, Clarksville, IN, USA, pp. 105-137.

Russell DJ (1982) Controls on shale durability: the response of two Ordovician shales in the slake durability test. Canadian Geotechnical Journal 19(1): 1-13, https://doi.org/10.1139/t82-001.

Sabtan AA (2005) Geotechnical properties of expansive clay shale in Tabuk, Saudi Arabia. Journal of Asian Earth Sciences 25(5): 747-757, https://doi.org/10.1016/j.jseaes.2004.07.003.

Santi PM (1998) Improving the jar slake, slake index, and slake durability test for shales. Environmental and Engineering Geoscience IV(8): 385-396, https://doi.org/10.2113/gseegeosci.IV.3.385.

Santi PM and Koncagül EC (1996) Predicting the mode, susceptibility, and rate of weathering of shales. In Design in Residual Soils, Geotechnical and Construction Considerations (Matheson G (ed.)). American Society of Civil Engineers, New York, NY, USA, Geotechnical Special Publication, no. 63, pp. 37-55.

Senalp M and Al-Duaiji AA (2001) Qasim Formation: Ordovician stormand tide-dominated shallow-marine siliciclastic sequences, central Saudi Arabia. GeoArabia 6(2): 233-268.

Skempton AW (1953) The colloidal 'activity' of clays. Proceedings of the 3rd International Conference on Soil Mechanics and Foundation Engineering, Zurich, Switzerland, vol. 1, pp. 57-61.

Skempton AW (1964) Long-term stability of clay slopes. Géotechnique 14(2): 77-102, https://doi.org/10.1680/geot.1964.14.2.77.

Slater DE (1983) Potential expansive soils in Arabian Peninsula. Journal of Geotechnical Engineering 109(5): 744-746, https://doi.org/10.1061/ (ASCE)0733-9410(1983)109:5(744).

Vallejo LE, Welsh RA, Lovell WC and Robinson MK (1993) The influence of fabric and composition on the durability of Appalachian shales. In Rock for Erosion Control (McElroy C and Lienhart D (eds)). ASTM International, West Conshohocken, PA, USA, STP1177, pp. 15-28.

Zhu JJ and Deng H (2019) Durability classification of red beds rocks in central Yunnan based on particle size distribution and slaking procedure. Journal of Mountain Science 16(3): 714-724, https://doi. org/10.1007/s11629-018-5234-5.

\section{How can you contribute?}

To discuss this paper, please submit up to 500 words to the editor at journals@ice.org.uk. Your contribution will be forwarded to the author(s) for a reply and, if considered appropriate by the editorial board, it will be published as a discussion in a future issue of the journal. 